\title{
Research and Investigation on the Opening of Sports Venues in Colleges and Universities in Lanzhou to the Society
}

\author{
Honghai Li \\ College of Physical Education, Northwest Normal University, Lanzhou 730070, Gansu, China \\ 1139206562@qq.com
}

Keywords: Lanzhou City; college sports venues; current situation; countermeasures

\begin{abstract}
This study uses literature research, interviews, questionnaires and field surveys, logic and analytical comparison methods to apply the relevant theories of management, economics, sociology and physical education to the sports venues of Lanzhou Higher Education Institutions in Gansu Province. The status quo of the openness was investigated and analyzed. The research clearly defined the restrictive factors for the opening of sports venues in colleges and universities in Lanzhou to the society. Finally, it put forward the countermeasures and suggestions for the university to further open the sports venue to the society in an orderly and effective way. It is expected to provide policy as effective reference basis for relevant departments.
\end{abstract}

\section{Introduction}

With the general improvement of people's lives, the demand for fitness is growing, and the shortage of fitness facilities is highlighted. In this way, making full use of the existing stadium facilities resources, it is placed in front of the theoretical workers and stadium managers. The opening of college sports venues to the society can partially compensate for the inadequacy of the stadium facilities outside the school. The Sports Law of the People's Republic of China (1995) clearly stipulates that public sports facilities should be open to the public ${ }^{[1]}$. "National Fitness Articles" (2009) also pointed out that public schools should actively create conditions to open sports facilities to the public ${ }^{[2]}$.

\section{Definition of relevant concepts, current status of domestic related research and introduction} of research methods

\subsection{The meaning of opening colleges and universities to the society}

There is basically no disagreement about the connotation of the stadium, and there is a slight 
difference in the expression. This paper combines the definition of sports venues by Cao Jianxun and others, and gives the basic meaning of opening stadiums to the society in colleges and universities: under the premise of ensuring that schools complete normal physical education, sports training and sports competitions, extracurricular activities During the time and holidays, we will provide sports venues to the surrounding community, as well as to social organizations, organizations and collectives. It can be seen that the opening of college sports venues to the society means opening the stadiums (sites) of the school to other subjects besides the teachers and students of the school ${ }^{[3]}$. Sports venues can be divided into state-owned, individual, collective, foreign-funded, etc. according to the property rights. The ownership and use rights of the stadiums of the school are mainly owned by the state, which determines the attributes of their public products.

\subsection{Analysis of research status}

When the social stadium resources can not meet the people's physical fitness needs, the feasibility analysis of the school stadiums for opening to the outside is put on the agenda. In recent years, research on the opening of college sports venues to the public has been in full swing. These achievements have made the university sports stadiums open to the society in an orderly manner, and the use efficiency of the stadiums has made a meaningful exploration. The following is a summary of these results in accordance with the basic framework of scientific research.

\subsection{Adoption of research methods}

In the existing relevant literature, the application of empirical methods is generally emphasized, with empirical analysis combined with quantitative analysis. The following methods are mainly used.

(1) Literature research. Social science related theories, especially economics, management, and sociological perspectives are widely used;

(2) Interviews with experts and managers. Interviews and solicitation of meaning objects: college sports stadium management personnel in school sports, sports management and sports economy; content includes: importance analysis, how to order and effective comprehensive opening, and how to solve the contradiction between teaching and mass sports demand And so on.

(3) Field visits. Through on-the-spot investigations of colleges and universities, we can intuitively understand the status quo and problems of the opening and management of various venues.

(4) Questionnaire survey. The survey included the managers of the venues and the masses.

(5) Simple mathematical statistics and logic analysis.

\subsection{Analysis of research content}

Existing research has made a useful attempt to construct a reasonable and scientific theoretical analysis framework. The content of the research is mainly concentrated on the following aspects.

(1) Feasibility analysis;

(2) Analysis of constraints;

(3) Resource allocation and development and utilization of venues;

(4) Comparison of paid open and free open;

(5) Factors affecting paid openness, or affecting paid open profit The factors of the effect.

\subsection{Views and conclusions}

The viewpoints and conclusions are as follows:

(1) public forums have become open to the public; 
(2) the conditions for opening up to the society are basically mature, and there are many restrictive factors;

(3) the purpose of opening venues is not to pursue economic benefits, but In order to create greater social benefits, it is the embodiment of revitalizing existing sports resources and serving the public ${ }^{[4]}$.

\subsection{Review of related research}

The author believes that the existing research has the following shortcomings: the analytical framework is imperfect, the content arrangement is not systematic; the micro level analysis is not representative, or the experience is insufficient; the theoretical analysis is not sufficient in qualitative research, and the empirical analysis is not deep enough. It is considered that these problems need to be solved urgently: the mode of opening up to the society, such as meeting the actual operational mechanism of each university and the formulation of the plan; the problems and contradictions faced by them; the role of the administrative department and the university in which it should play;

\subsection{Introduction to the research methods used in this paper}

This study takes the stadiums of 10 colleges and universities in Lanzhou as the research object, and analyzes and discusses the status quo and constraints of the opening of college sports venues to the society. The study uses a combination of empirical analysis and normative analysis, mainly using these specific methods.

(1) Literature data method. Mainly consulted the relevant sports, economics and management literature and journal materials, and initially drafted the writing framework.

(2) Interview method. Ask relevant experts on the use of research methods and the selection of research content.

(3) Questionnaire survey method. Based on the research purpose, content and expert opinions, the "College Student Supervisor Leadership Questionnaire" and the "Enrollment Residents Questionnaire" were designed. Ten colleges and universities in Lanzhou were selected for questionnaire survey. The selection of the sample mainly considers the following factors: the differences of the school, the convenience of obtaining information, and the conditions of the research. From April 2017, the questionnaires were issued to the residents who entered the school, and the validity and reliability of the questionnaires were tested.

(4) Field inspection method. Field visits were conducted to all sample schools to obtain first-hand information as much as possible.

(5) Mathematical statistics and logic analysis.

\section{Research results and analysis}

This part includes the status quo of the opening of college sports venues in Lanzhou to the society, the surrounding people's participation in sports activities and the constraints of the opening of the venue.

\subsection{Basic conditions of the opening of the venue}

The survey shows that the overall situation of colleges and universities in Lanzhou is open to the public. Among the 10 universities surveyed, the stadiums of all universities are open to the public or partially open to the public, but they are mainly open (7kinds). This also shows that the relevant managers of the school can recognize the basic functions and responsibilities of public venues serving the public. The opening of school sports venues to the society reflects the social service and 
public welfare of colleges and universities, and meets the requirements of the development of the new era. The survey found that Lanzhou City's college sports stadiums are open to the public to serve the broad masses of fitness needs, with the main purpose of pursuing social benefits, which also highly reflects the sense of social responsibility of colleges and universities. According to the survey, there are 4 colleges and universities in Lanzhou that open the stadiums and gymnasiums at no cost, and the six colleges and universities are open to the public with free and unpaid compensation. The combination of paid and unpaid will facilitate the management of sports venues in colleges and universities, and enable residents to participate in physical exercise in an orderly manner ${ }^{[5]}$. Lanzhou City University sports venues are open to the public in general after school hours, that is, morning and evening, weekends and holidays. Open objects present a diverse trend. In addition to the teachers and students of the school, the main objects open to the community: surrounding community residents, social groups, neighboring brother units. This also shows that the biggest beneficiaries of the opening of college sports venues are the families and individuals in the surrounding communities, nearby social groups and organizational organizations. In addition, the open sports projects are mainly: basketball, volleyball, table tennis, badminton and various track and field events. Due to the shortage of venue resources for table tennis, badminton and other projects, colleges and universities often choose to open up in the form of paid openness. The standard 400-meter sports field is open free of charge.

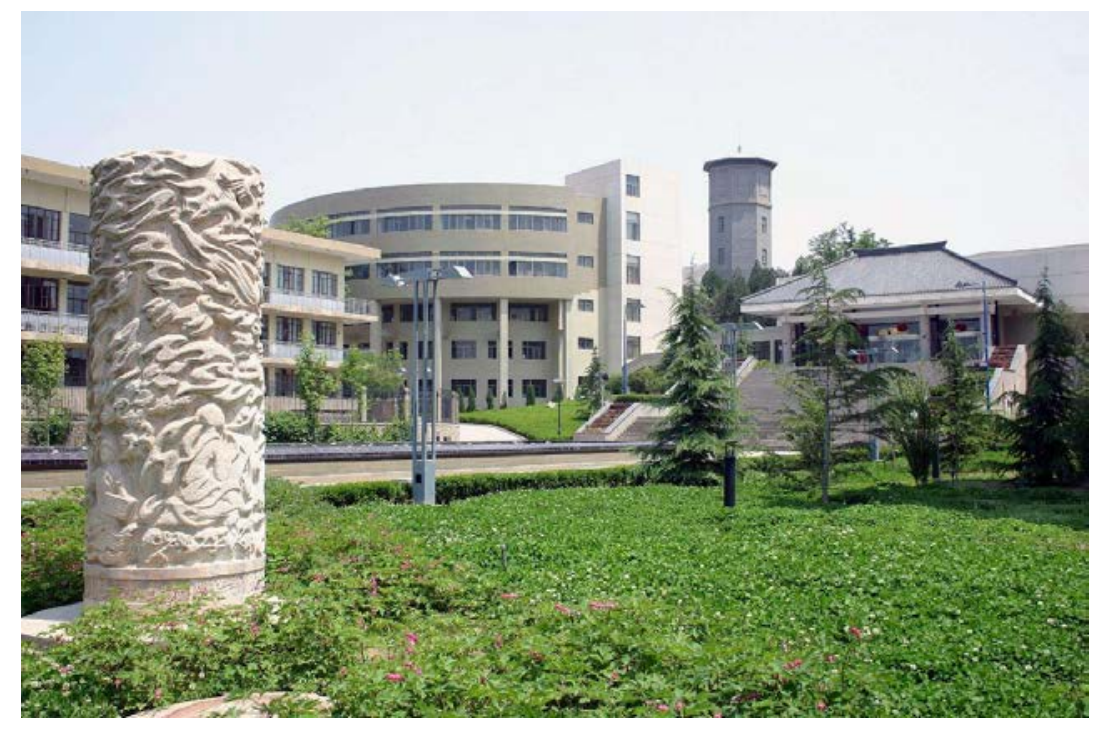

Fig. 1 The beautiful sports venue of the university

Only through the scientific and standardized management can the stadiums create better social and economic benefits. According to the survey, only half of the universities have established an open management system for the venues. In addition, the managers are mainly administrative cadres, with part-time management as the mainstay. Obviously, the management of the opening of college sports venues is still at a low level and inefficient stage.

\subsection{Status of residents participating in sports activities}

Among the respondents, residents who participated in physical exercise were mostly middle-aged and older people aged over 50 (about 56\%) and those under 50 years old accounted for $44 \%$. In terms of gender structure, there are more male residents than females. According to the survey, the time periods for residents to participate in sports activities are evening, morning and weekends or holidays. It can be seen that the peak of residents' fitness at night. According to the survey, residents generally 
have more than three activities per week, and they all have the habit of participating in physical exercise. According to the survey, residents hope to get help in physical fitness technology, and nearly half of the residents hope to have the opportunity to participate in various sports organizations $^{[6]}$.

The survey shows that the reason why the choice to go to the gymnasiums in colleges and universities is mainly because the venues are close to their own homes, the personnel and cultural atmosphere in the colleges and universities are strong, and the quality of the stadiums is good. At the same time, the exercise of the masses believes that the stadiums are open to the public, the lack of sports venues, the quality of the venues and the opening hours are not reasonable. But overall, residents are satisfied with the services provided by the school.

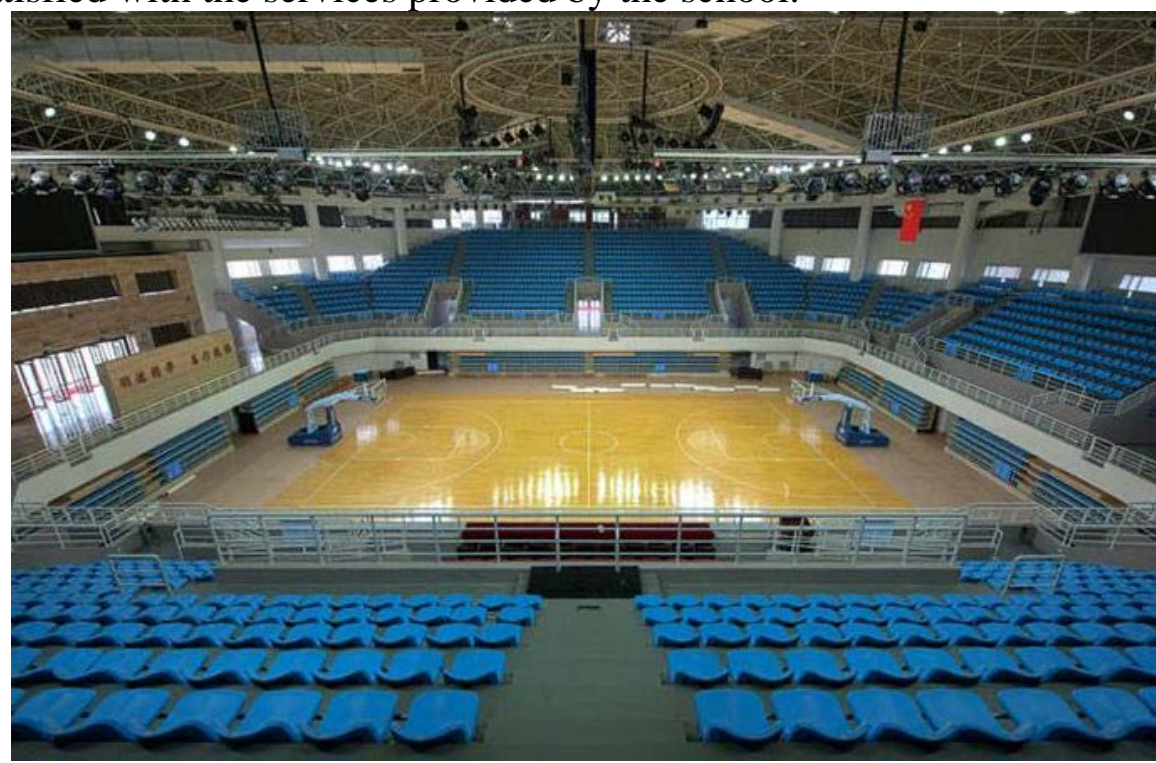

Fig. 2 University sports venues are fully functional to meet the needs of the open

\subsection{Analysis of restricted open factors}

The constraints of the sports venue conditions. The results of the fifth national census show that the stadium resources in Gansu Province are mainly concentrated in primary and secondary schools (including secondary vocational schools), and college sports venues only account for $4.0 \%$ of the total number of provinces. In addition, the university's successive expansion of enrollment in these years has resulted in a low student-to-source ratio, and the quality of colleges and universities in Lanzhou is generally not high. From field trips and interviews, it is known that colleges and universities must ensure the physical and mental needs of students in class and extracurricular activities, and meet the fitness needs of the surrounding residents. This is indeed a problem.

Trouble with security factors. The security issue is a common concern and concern of all parties, and it is also an urgent problem to be solved in the opening of public venues. Colleges and universities open to the public to focus on serving the society, this is a public welfare act. As the frequency of use of venue facilities and equipment increases and losses increase, maintenance costs will also rise sharply. There may also be various things that affect the normal teaching order of the school, such as various safety hazards. Therefore, colleges and universities open up in the stadium and naturally do not dare to let $\mathrm{go}^{[7]}$.

Analysis of management system factors. In order to improve the efficiency of the use of stadium resources, a good management system is indispensable. The survey found that most colleges and universities did not have relevant management rules and regulations. This is mainly because the 
opening of the stadium is related to education, sports, industry and commerce, taxation, price, public security and other departments. At the same time, the boundaries of rights and powers are not clear, which in some cases creates a disorderly reality.

\section{Conclusions and Recommendations}

The overall situation of the opening of colleges and universities in Lanzhou to the society is good, and the masses are satisfied. However, it is also plagued by many factors that are mainly lacking in stadium resources. To this end, the research team recommends the following:

(1) Increase government investment, innovate the investment and financing system of sports venues, and try to expand the source of funds for stadium construction and improve the quality of stadiums and facilities.

(2) Formulate and improve the management rules and regulations of various sports venues to ensure orderly and effective opening.

(3) Introduce relevant and mature insurance mechanisms to solve the worries of colleges and universities in the opening of sports venues.

(4) Strengthen interaction and contact with surrounding communities, and find new ideas for the orderly opening of sports venues.

\section{References}

[1] Standing Committee of the National People's Congress. Sports Law of the People's Republic of China. October 1995.

[2] State Council. National Fitness Column. October (2009).

[3] Cao Jianxun, et al. Sports industry management. Wuhan: Hubei Science and Technology Press, (1994), p.163.

[4] Xu Shenghui. Research on the status quo of colleges and universities in Gansu Province opening to the society. Lanzhou: Northwest Normal University, (2011) No. 8.

[5] Liu Xiaofei. Research on the opening of college sports venues in Yangpu District, Shanghai to the society. Shanghai: Shanghai Institute of Physical Education.,(2010) No. 32.

[6] Du Ping. Status Quo and Analysis of Sports Fields in Gansu Province. Gansu Science and Technology, Vol. 7 ((2008) No. 24, p.12-14.

[7] Wang Xiaopeng. The current situation and analysis of college sports venues in Chongqing serving the national fitness. Chongqing: Chongqing University,(2010) No. 36. 